\title{
Oral health awareness, promotion of home oral self-care, and professional oral health care among young mothers and their babies: a pilot project
}

\author{
Yvonne AB Buunk-Werkhoven ${ }^{1 *}$ and Selma Y Burrekers ${ }^{2}$ \\ ${ }^{1}$ SPOH ARTS - International Oral Health Psychology , Amsterdam, Netherlands \\ ${ }^{2}$ Oral Hygienists Group-Groningen, Netherlands
}

\begin{abstract}
Background: The purpose of this pilot-project among young mothers and their babies was to determine the impact of a low threshold approach for the promotion of oral health, and to understand the engagement with oral self-care. Understanding factors which may influence young mothers' responsibility and ability to deliver their roles as caregivers is necessary to ensure that their babies receive preventive care in a (cost)-effective way.

Methods: Two workshops aiming to reach a 'young mothers group' at the Social and Legal Services (MJD) in Groningen were undertaken. The young mothers -17 up to 24 years- completed an index for determining and evaluating personal oral hygiene behavior. To support the informative intervention, the young mothers were invited to visit the Oral Hygienists Group-Groningen for a professional oral health screening. For participating in the workshop the mothers were rewarded with a toothbrush for themselves and with a children's toothbrush, including toddler toothpaste.

Results: At the first workshop, all mothers have babies and toddlers. It was determined that two-third of the young mothers, brushed their teeth 2 times per day with a manual tooth brush, and three-quarters of them reported to brush the teeth at least before to go to sleep. Interdental aids, such as the use of floss or toothpicks were hardly used. In the second workshop the previous young mothers group was expanded with a 7 month pregnant woman. During this repetitive informative meeting, the emphasis was mainly on health awareness and oral health care of the babies and toddlers. Enthusiasm and active participation had not been converted directly into a visit or a free consult to the oral hygienist.
\end{abstract}

Conclusion: This exploratory approach may improve the mothers' knowledge; it may encourage their home self-care. In addition, an adequate prevention policy tailored to this target group, or to the individual young mother, can be developed.

\section{Introduction}

Oral health promotion is at least as important as prevention of oral diseases. Nowadays, the main focus may be, "Promotion of optimal oral health is key". Oral health promotion is a precautionary process in which people are learning somehow to improve their oral health conditions through a broad range of activities and practices. In other words, it refers to the process by which individuals or targets groups are able to gain more control over the determinants of their oral health, and improve their oral health $[1,2]$.

Recently, previous studies found that past oral health education and promotion interventions (OHEPIs) are effective and have positive impacts on dental visits, attitudes, on tooth brushing and flossing during short term post-intervention, even among children [3,4].

Optimal oral health can be considered as a core component of general (public) health and well-being [5]. In the Netherlands, intervention programs are developed and introduced for the oral health professionals to apply in their oral health practices, for instance 'GigaGaaf!' [6] and 'Gewoon Gaaf' [7]. An article in a local newspaper -Groninger Gezinsbode of December 1 in 2011-, about life experiences in a young women group of the Center for Youth and Family (CJG) was the inspiration for this voluntary initiative. The pilot-project was set up by two oral hygienists and focussed on oral health awareness and intentional behavioral change of young mothers to take responsibility for their oral health and oral self-care, including the health care of their babies and toddlers. Adequate daily home oral care and regular visits to an oral health professional are the best guarantee for maintaining oral health, and by developing personal skills and performing daily oral self-care, especially starting tooth brushing from the beginning of one's life -by young mothers- and continuing from a young age -by the toddlers themselves-, most common oral diseases can be prevented [8]. However, when preventive oral health care interventions are provided by oral health professionals and implemented at for instance a center for youth and family or at primary schools, people and children often are not that well informed, and don't perform the appropriate behavior for the long-term [2-4].

The present pilot-project among young mothers and their babies was to determine the impact of a low threshold approach on the

Correspondence to: Yvonne A.B. Buunk-Werkhoven, $\mathrm{PhD}, \mathrm{MSc}, \mathrm{RDH}$ Rozenstraat 74a, 1016 NX Amsterdam, Netherlands; Tel: +31651873389; E-mail: yvonne@spoh-arts.com

Key words: Oral health awareness, Young mothers (re-)brushing behavior, oral health-educating and health-promoting intervention, oral hygienist

Received: December 03, 2017; Accepted: December 26, 2017; Published: December 29, 2017 

a pilot project

promotion of oral health, and to understand engagement with oral self-care. Understanding factors which may influence young mothers' responsibility and ability to deliver their roles as caregiver is necessary to ensure that their babies receive preventive care in a (cost)-effective way.

\section{Methods}

This pilot-project for study with human subjects was conducted according to universal ethical principles. Participation of the young mothers group' in Groningen was on a voluntary basis, the mothers were informed what participation implied, and no pressure was exerted to take part in a test for determining and evaluating the personal oral hygiene behavior during the interactive workshops by a qualified psychologist and oral health professional. The oral hygienist conducted the oral health education to the 'young mother group' with a natural routine method based on her own professional practice experience. The ethical board, Central Committee on Research Involving Human Subjects, affirms that studies which requires filling in a survey/test for one occasion does not fall under the scope of the Medical Research Involving Human Subjects Act [9].

Both authors started an interactive workshop on oral health awareness, a -so called- oral health-educating and health-promoting intervention in a center for 'young mothers' in Groningen, a city in the Northern part of the Netherlands. This pilot-project is considered as a unique opportunity to promote oral health knowledge and young mothers' and their toddlers' tooth brushing behavior (oral self-care) in a casual way, thus in the first time outside the walls of professional oral health practices. By monitoring and evaluating the project the outcomes or positive effects could be informative for the policy officer within MJD, and may be performed in the future for other target groups, such as the 'PREGNANCY', the 'Mothers inform Mothers' (MIM) group and/or the 'Parent \& Child' morning group in Groningen.

The emphasis in the two powerpoint presentations: 'Your mouth healthy and refreshed? Go to an oral hygienist!" were mainly on the awareness of oral health. In general, common 'Consumers' questions about oral health care and various other health topics were discussed and explained. During the first workshop, the young mothers completed an index for oral hygiene behavior (OHB) [10]. The focus of the first presentation was on facts -typically- for the young mothers and laterally on the oral health of the baby or the young child. An example of the text was: 'Did you know that ... a healthy mouth contributes to a healthy body and that it can give you a good feeling?' To support the informative intervention, the young mothers were invited to visit the Oral Hygienists Group-Groningen for a professional oral health screening. For participating in the workshop the mothers were rewarded with toothbrush for themselves and with a children's toothbrush, including toddler toothpaste. In the second workshop, the emphasis of the presentation was mainly on the oral health care of the baby/toddler, for example: 'Did you know that ... a healthy mouth contributes to healthy physical development of a baby/toddler?'.

A half year after the first meeting, 10 young mothers received a telephone call, and were personally invited by the oral hygienist of the Oral Hygienists Group-Groningen to visit her practice for a free consult.

\section{Results}

On paper, the 'young mothers group' consisted of 15 participants; the youngest was 17 years old and the oldest was 23 years old. All mothers had babies and toddlers, aged from zero to 6 months, and from about 1.5 to 4 years old. In the early Spring, at the first meeting, eight mothers of the group were present; three mothers were ill, and four young mothers were absent without any notice. The enthousiastic and active participation of the young women was converted into a concrete visit to the Oral Hygienists Group-Groningen. The oral hygiene behavior of the young mothers was established with the MondiX ${ }^{\oplus}$ [11], and it was determined that two-third reported to brush their teeth twice per day with a manual tooth brush, and three-quarters of them reported to brush the teeth at least before to go to sleep. About a half of the young mothers brushed only one minute (four mothers brushed 2 minutes or longer. Three-quarters of the young mothers used toothpaste with fluoride ( 3 mothers reported not to know). Interdental aids, such as the use of floss or toothpicks were hardly used, and almost the half of the young mothers cleaned their tongue every day.

In the beginning of the Summer, approximately three months after the first informative meeting, the previous 'young mothers group' consisted -on paper- of 11 participants, including five new young mothers. One of the participants was pregnant for 7 months. Five mothers of this total group were present; five mothers were absent and one mother came later on. This young mother group had asked for a follow-up meeting in which they would like to get more information, in particular, about the oral care of their baby or toddler. So, in this repetitive informative meeting, the emphasis was mainly on health awareness and oral health care of the babies and toddlers, and this approach was more in line and better received by the participants. Unfortunately, again, it was not supportive enough for a visit to, or free consults by the the oral hygienist.

After the discussion in the workshops, the young mothers valued limitation of sugary foods and drinks consumption (snacks) as not important, and reported not willing to try to limit the frequency of consuming sugary foods and drinks. Also, they were not aware of the fact that toothbrushing should be performed at least one hour after exposure of acidic soft drinks.

In the Autumn, even though the young mothers were called by the oral hygienist herself, out of 10 mothers, only six mothers were reached and invited by telephone, and finally four mothers had made an appointment to visit to practice for a free consult. In the end, just two new young women -one young mother (case report I) and one woman who was pregnant (case report II)- received an oral health screening by the oral hygienist in the practice of the Oral Hygienists GroupGroningen.

Case report I: Daniela, 23 years came with her daughter Danilla, 3 years. She did not attend one of the two previous MJD 'young mothers group' oral health education meetings. Once she had visited an oral hygienist who works in a dental practice with a dentist. During the consult, her daughter started to cry and did not want to take place into the treatment room at first, but later on she came closer and closer to the chair to watch her mother (with her cuddle elephant in her hands). Daniela was right-handed; she valued her oral health condition with a number: 7 (on a scale of 0-10). She reported to smoke and she had some white spots on her teeth, including a few calculus/tartar in the lower front [this has been removed by the oral hygienist]. In the upper and lower front teeth she had a splint (because of having orthodontic braces in the past). All her wisdom molars were well erupted. As in daily practical use in Dutch oral health services, the DPSI score [12] was determined for each sextant on the basis of the site with the most severe periodontal condition. Daniela her gingival/periodontal condition was as follows: DPSI-score 0: 'healthy gum' up to DPSI-score 1: 'slightly gingivitis'. There was an enamel defect in the 27 (molar in the left upper jaw). Professional oral hygiene instructions: For Daniela, to be able to 

a pilot project

brush her molars in the backyard of her mouth, she was recommended not to open her mouth too far when brushing. She had to keep her mouth that closed, in that way that she could keep her cheek aside with the toothbrush. She was advised not to brush too hard; because of some light recessions. Her question about the toothpaste was answered that a specific brand was not the case or did not matter, however, she had to use toothpaste with fluoride and she also was advised not to rinse her mouth with water, directly after tooth brushing. A recall appointment in 2 months was recommended (Figure 1).

Case report II: Hieke, 22 years and pregnant for 27 weeks. She did not attend the two previous MJD 'young mothers group' oral health education meetings, and she had never visited an oral hygienist before. She has been throwing up a lot because of her pregnancy. Hieke was right-handed; she valued her oral health condition with a number: 7 (on a scale of $0-10$ ). She reported not to like her teeth very well, but she had no complaints. In the upper and lower front teeth she had a splint (because of having orthodontic braces in the past). All her pre molars were extracted, and her four wisdom molars were well erupted. Hieke her DPSI score [12] was determined for each sextant and her gingival/ periodontal condition was as follows: DPSI-score 1 up to DPSI-score 2: 'gingivitis. Professional oral hygiene instructions: for Hieke, because of her pregnancy she was advised to brush carefully and to have regular professional cleaning and polishing. A recall appointment in 2 months, including gingival treatment was recommended (Figure 2).

\section{Discussion}

The aim of this pilot-project among young mothers and their babies was to determine the impact of a low threshold approach on the promotion of oral health, and to understand engagement with oral self-care. Understanding factors which may influence young mothers' responsibility and ability to deliver their roles as caregiver is necessary to ensure that their babies receive preventive care in a (cost)-effective way. Observational and descriptive findings demonstrate that overall the interactive workshops were certainly appreciated by the 'young mother group'. Informal and spontaneous participation was rewarded by a toothbrush and toothpaste.

Moreover, the young mothers' participation in the two workshops, including the completed index of $\mathrm{OHB}^{10} / \mathrm{MondiX}^{\bullet}$ [11], provided not only insight in their oral health knowledge and oral self-care, but also in their intentions to supervised brushing and re-brushing their toddlers' dentition. Furthermore, the mothers' actively participation show the impact of such an approach may have on toddlers tooth brushing

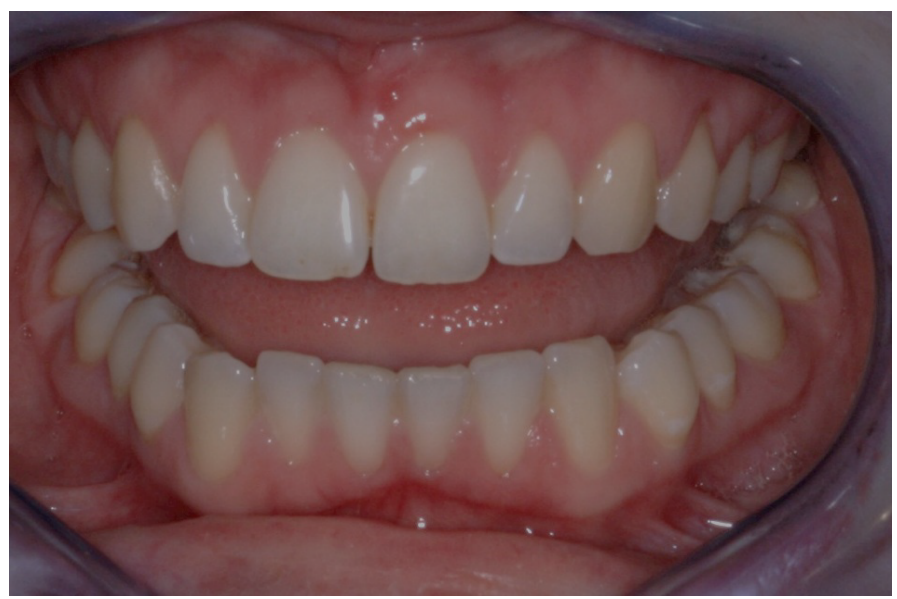

Figure 1. Daniela's mouth (C) S.Y. Burrekers (Oral Hygienists Group-Groningen)

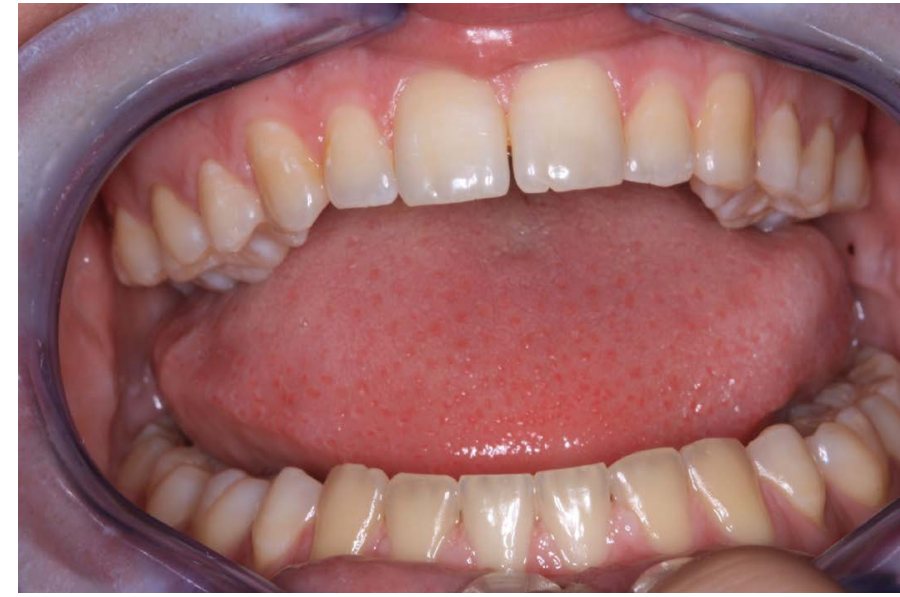

Figure 2. Hieke’s mouth (C) S.Y. Burrekers (Oral Hygienists Group-Groningen)

Hieke's, their own opinions towards oral hygienists and their intentional behavioral change to limit sugary foods and drinks consumption. In addition, it may improve young mothers' knowledge, and the primary findings indicate at least a positive short-term impact. In line with a previous study, oral health-educating and health-promoting intervention, leaded by oral hygienists, may not only encourage awareness and/or willingness of the parents/carers to take better care of their children's dentition, in the end, it may encourage children's own oral self-care too [13]. In addition, oral hygienists, as specialized and highly work engaged professionals, could play a significant role in promoting oral health and preventing oral diseases [14]. This pilotproject has some limitations, because it included a rather small group of young mothers in Groningen. Another shortcoming is that, even this pilot-project showed that a specific population-based, carefully and effectively carried out program of personal oral self-care may play an important role in the improvement of oral health awareness, it seemed that the young mothers are in the first or second phase of the Transtheoretical Model of Behaviour change [15]: In the first phase, the pre-contemplation phase, individuals do not intend to change their own oral hygiene behavior, either because they do not know why they should do, or because they know why, but they think that the desired advice is not necessary for themselves. Also, it is possible that these mothers feel that they will not succeed in following and acting all these instructions. In the second phase, the contemplation phase, individuals do acting yet, but they do consider changing their oral hygiene behavior. They think about the consequences of tooth brushing differently, and they wonder how likely it is for them to perform the desired oral hygiene behavior. Only, Daniela and Hieke were in the fourth phase; the action phase as described in the case reports (I and II).

To conclude, health awareness is a very important first step when it comes to health behavioral change, and therefore the different phases of the model of behavior change [15] have to be involved in following projects of research. The use of Intervention Mapping (IM) [16] as a protocol for developing theory-based and evidence-based health promotion programs is conditional, and further research to refine the effects of oral health promotion is necessary. Especially, for oral hygiene behavior as a habit behavior, the theory of habitual behavior [17] can be applied in oral health interventions. This theory can be seen as a supplement to the Theory of Planned Behavior $[1,2,10]$. If a certain task, such as tooth brushing, is performed regularly, people do not always weigh the pros and cons. It is also not necessary for people to check whether they have the idea that they are capable of carrying out 

a pilot project

this focal behavior. If the situation recurs often, there will eventually be a habit or automatic action without a conscious choice process. The following five aspects form the basis for habit formation: 1) repetition 2) automatically, 3) frequency, 4) personal style, 5) unconsciously and 6) efficient. To apply these aspects in persuasive oral health communication [18], Motivational Interviewing is a recommend method [19]. A best practice example of an IM and theory based oral health promotion program for toddlers and young children (and parents/carers), initiated and developed by the GGD Amsterdam is called 'Trammelant in Tandenland' [20]. Another example of an evidence-based public play and learning approach on the promotion of oral health and oral self-care of children and their parents, or carers is called the 'Kidsfabriek' [21].

\section{Acknowledgments}

Many thanks to Hedda Rasterhoff for her valuable professional help and support in this pilot project. The toothbrushes and toothpaste were kindly supported by TePe and GABA in the Netherlands. The authors declare that they have no competing interests. In 2012, this project was submitted for the NMT-Award Innovation Oral Health for Children [22].

\section{References}

1. Buunk-Werkhoven YAB (2010) World White Teeth: Determinants and promotion of oral hygiene behavior in diverse contexts. PhD Thesis. University of Groningen.

2. Buunk-Werkhoven YA, Burrekers SY, Jongboer A, Quant DF, van Maanen-Schakel NW (2011) Determinants of oral hygiene behavior in the Dominican Republic. Int Dent $J$ 61: 328-333. [Crossref]

3. Ghaffari M, Rakhshanderou S, Ramzankhani A, Noroozi M, Armoon B. Oral health education and promotion programmers: Meta-Analysis of 17-year intervention. Int $\mathrm{J}$ Dent Hyg. 2018;16(1):59-67. [Crossref]

4. Ghaffari M, Rakhshanderou S, Ramzankhani A, Buunk-Werkhoven YAB, Noroozi $\mathrm{M}$, Armoon B. Are educating and promoting interventions effective in oral health?: A systematic review. Int J Dent Hyg. 2018;16(1):48-58. [Crossref]

5. Glick M, Williams DM, Kleinman DV, Vujicic M, Watt RG, et al. (2016) A new definition for oral health developed by the FDI World Dental Federation opens the door to a universal definition of oral health. J Am Dent Assoc 147: 915-917. [Crossref]

6. TNO Innovation for life (TNO), GigaGaaf! TNO rapport R11201|060.00299 ii (C) 2017 TNO https://www.tno.nl/en/focus-areas/healthy-living/roadmaps/prevention-workhealth/healthy-and-safe-upbringing/oral-hygiene-for-youngsters/
7. Ivoren Kruis (Ivory Cross), 'Gewoon Gaaf' Available from: http://www.ivorenkruis.nl/ Gewoon-Gaaf.html and http://www.ivorenkruis.nl/Hou-je-mond-gezond!.html

8. Duijster D (2015) Family matters. The role of parental and family-related psychosocial factors in childhood dental caries. PhD Thesis. University of Amsterdam.

9. Central Committee on Research Involving Human Subjects (CCMO). Questionnaire research. http://www.ccmo.nl/en/questionnaire-research.

10. Buunk-Werkhoven YA, Dijkstra A, van der Schans CP (2011) Determinants of oral hygiene behavior: a study based on the theory of planned behavior. Community Dent Oral Epidemiol 39: 250-259. [Crossref]

11. Buunk-Werkhoven YAB, Dijkstra A, Schuit K (2012) "Identification and evaluation of adequate oral hygiene behavior: The development of the MondiX®". 140th American Public Health Association (APHA) Annual Meeting in San Francisco, CA. https://apha. confex.com/apha/140am/webprogram/Paper259963.html

12. Van Dannis H, Steures R, Sipos P (2010) [Your gum gets a number]. Avenhorn: NVvP 2: $1-6$

13. Saied-Moallemi Z, Virtanen JI, Ghofranipour F, Murtomaa H (2008) Influence of mothers' oral health knowledge and attitudes on their children's dental health. Eur Arch Paediatr Dent 9: 79-83. [Crossref]

14. Buunk-Werkhoven YA, Hollaar VR, Jongbloed-Zoet C (2014) Work engagement among Dutch dental hygienists. J Public Health Dent 74: 227-233. [Crossref]

15. Prochaska JO, DiClemente CC, Norcross JC (1992) In search of how people change. Applications to addictive behaviors. Am Psychol 47: 1102-1114. [Crossref]

16. Kok G, Gottlieb NH, Peters G-J Y, Mullen PD, Parcel GS, et al. (2016) A taxonomy of behavior change methods; an intervention mapping approach. Health Psychol Rev 10(3): 297-312. [Crossref]

17. Verplanken B, Aarts H, van Knippenberg A, van Knippenberg C (1994) Attitude versus general habit: Antecendents of travel mode choice. J Appl Soc Psychol 24: 285-300.

18. Buunk-Werkhoven YAB, Dijkstra A, Jaso ME, Acevedo S, Parodi Estellano G, et al. (2011) Persuasive oral hygiene communications in Uruguay and Spain. Cross-cultural Communication 1: 1-16.

19. Miller WR, Rollnick S (1991) Motivational Interviewing. New York: The Guilford Press.

20. Trammelant in Tandenland - an oral health promotion program for children. https:// www.trammelantintandenland.nl/?page $=$ ggd_theoretisch_kader

21. Buunk-Werkhoven YAB, Takrovskaja K, Steverink-Jorna LM. Kidsfabriek: Oral health awareness and promotion of oral self-care during a learning and play event for children and parents in The Netherlands. Annual Clin J Dent Health. 2018:7:22-25.

22. NMT-Award Innovations Oral Health for Children. https://www.dentalinfo.nl/actueel/ nmt-award-innovatie-mondzorg-bij-kinderen/

Copyright: (C2017 Buunk-Werkhoven YAB. This is an open-access article distributed under the terms of the Creative Commons Attribution License, which permits unrestricted use, distribution, and reproduction in any medium, provided the original author and source are credited. 